\title{
Influence of Computer-aided Instruction Model on Business English Writing Teaching Effect
}

\author{
https://doi.org/10.3991/ijet.v13i03.8396 \\ Xuefeng Li \\ Xian Fanyi University, Xi'an, China \\ Maqiangking@163.com
}

\begin{abstract}
To guide the college students through the Computer-aided Technology (CAT) to make writings of business English (BE) in the new teaching model, resources and methods, this paper carries out the application of CAT in $\mathrm{BE}$ writing teaching. It analyses the disciplinary characteristics of BE writing, conducts the BE instruction scheme design in the models of interactive teaching, writing teaching and inquiry teaching respectively on the basis of the learning theories such as humanism etc., and then develop the teaching contract experiment accordingly. Two parallel classes were randomly selected as objects of study, where the experimental class applied the Computer-aided Instruction (CAI) method, while the contrast class followed the traditional teaching methods; then the quantitative and qualitative analysis for one-semester teaching application was made by the after-experiment scores of BE writings in these two classes. The study in this paper verifies the positive role of CAT in BE writing, and also offer the effective guidance for improving the BE writing teaching level by CAT.
\end{abstract}

Keywords - Computer-Assisted Language Learning (CALL), computer-aided technology (CAT), computer-aided instruction (CAI), business English (BE), instruction scheme, contrast experiment

\section{Introduction}

Originated in the 1960s in America, Computer Assisted Language Learning (CALL) has become an important supplementary aid for foreign language learning in the past half-century; with the rapid development of computer network technology and popularization of computer software, CALL was promoting the reform of English teaching model [1]. The CALL, being able to optimize the resource allocation, improve the learner autonomy and realize personalization and automatization of the teaching model, have been applied all in listening, speaking, reading and writing of English learning, with certain positive effect. As one important skill of business communication ability and technique for college students, BE writing is required to be appropriate, accurate and courteous; learning the BE writing needs the guidance of accurate, professional and timely web-based courses [2]. 
In recent years, the domestic scholars have applied the computer multi-media aided technology such as PowerPoint, Macromedia Flash and Adobe Photoshop etc. to study the English teaching at home, and verified the validity of multi-media aided technology by interviews and tests [3]. Besides, CALL teaching model has been widely adopted in the English learning for the college students, esp. the E-learning platforms, including the American National English Corpus, British National English Corpus, khan Academy and Net-Ease Open-Course et., offer the convenient knowledge platforms for the English learning [4]. But despite the wider application of CAT in the English teaching, few professional studies were made for the CAT application into the professional English skill learning. It was the same for the BE writing: there were almost no effect-analysis research on the CAT function in the BE learning of the college students [5].

Based on it above, this paper aims to conduct applied study of CAT in BE writing teaching. It firstly reviews the BE writing and the related learning theories, and applies the CAT to design the BE interactive teaching, collaborative teaching and inquiry teaching; then develops and carries on the experiment by the comprehensive design of experiment objective, hypothesis, procedures and results analysis etc., and finally makes the related conclusion. The study in this paper is the effective supplementation to the computer information of English for Specific Purpose (ESP), being of great significance for improving the teaching level of BE writing.

\section{Theoretical basis}

\subsection{Subject characteristics of BE writing}

BE means the English language applied in BE environment, one of ESP. BE writing is a course of technical ability for the graduate seniors in such majors as international business, foreign trade, international finance and international marketing etc., designed to cultivate their capacity of business communication in written English for various purpose of business [6].

$\mathrm{BE}$ writing has given text features and writing methods, and the BE teaching should focus on these two aspects [7]. In terms of text features, the writings must vary in different occasions, reflecting the changes in terms of wording, sentence pattern, figure and text structure; while BE writing is required to be appropriate, accurate, courteous, clear and concise [8]. Refer to Fig 1 for the contrast between common writing and BE writing in PowerPoint courseware.

These are the two letters to decline the charity fund application of one applicant. The first letter didn't follow the BE writing norm, being too straight forward and crude; with the wording "regret" and then "reject", the whole letter was frustrating for the reader, because the writer had stronger subject consciousness in the ice-cold tone. However, the second letter was more acceptable for the reader by stating the reason and declining politely; also, it expressed compliments for the applicant's attitude by the wordings "congratulate you on your initiative", and welcomed the applicant to make the show next year [9]. The second letter is favourable for the donation commit- 
tee represented by the writer to set up or consolidate its public image of generosity and friendliness, conforming to the BE writing style.

\section{English Business Writing Teaching Case}

We regret that we are unable to give financial support to your proposal. We have many requests for funds and have already committed our budget for charitable giving for this year. Unfortunately we have to reject many ventures such as yours, since we have only so much to distribute.

Every year in February our Donations committee meets to discuss deserving appeals for funding, such as your request for support of the Montrose Revue. Your proposal arrived in March, after we had already made our selections for this year. Our budget for charities is now fully committed and we are therefore unable to help you at this time. If you plan to make the show an annual event, we will certainly add your proposal to the list for consideration next year. Please let us know before January 31 . In the meantime, I wish your every success with this year's revue and congratulate you on your initiative.

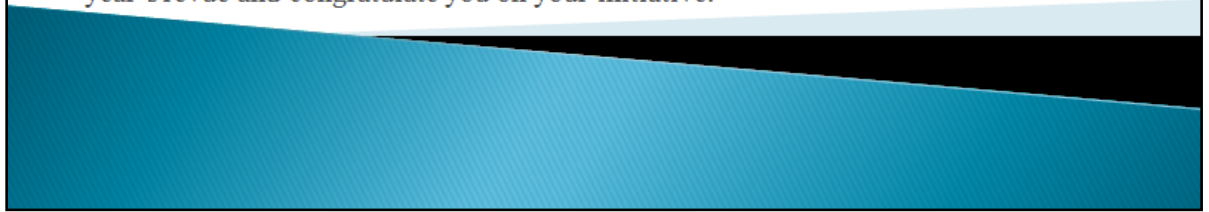

Fig. 1. English Business Writing Teaching Case Comparison

\subsection{Review of learning theory}

Humanism learning theory. Initiated in America in the 1950s-1960s, the Humanism learning theory, based on the humanistic psychology, emphasized on the learners' instinct and talent, and required to highlight their interests and hobbies [10]. The humanism theoreticians mainly classify the learning into two types: meaningless learning and meaningful learning. Meaningless learning means for the students to learn the forgettable syllables and words etc; the meaningful learning results in the great changes of the students' attitude, behaviour and personality, not only enriching their knowledge, but also learning to communicating with others.

Constructivism learning theory. As one branch of cognitive psychology school, the constructivism includes three main theoretical points: 1 . The learning process is the learners' re-construction of the original cognitive structure according to their own interests; 2. Constructivism emphasizes on the learning importance, insisting that learning environment plays a key role in learning effect; 3 . Constructivism thinks that the learner is the subject of both learning and cognitive behaviour; only by improving the learners' cognitive ability, their learning level would be promoted [11].

Collaborative learning theory. The collaborative learning theory was firstly originated in America in the 1970s. Collaborative learning means to promote the mutual 
help in group and mutual competition between groups in the group-learning model. It has delivered better empirical results in the actual teaching application, esp. cultivating the learners' English learning initiatives. The collaborative learning theory at substantial progress was one kind of creative and effective strategy [12].

\section{Computer-aid instruction (CIA)-based scheme design for BE writing}

\subsection{Interactive business teaching model form}

The interactive teaching model includes man-man interaction, man-machine interaction and learner-learning content interaction. Then the interactive forms would be one-to-one, one-to-many, and many-to-many.

The CALL-based BE interactive writing teaching model was designed to help the students achieving the BE writing teaching requirements [13]. It highlights the individualized and interactive teaching, and autonomous and collaborative learning.

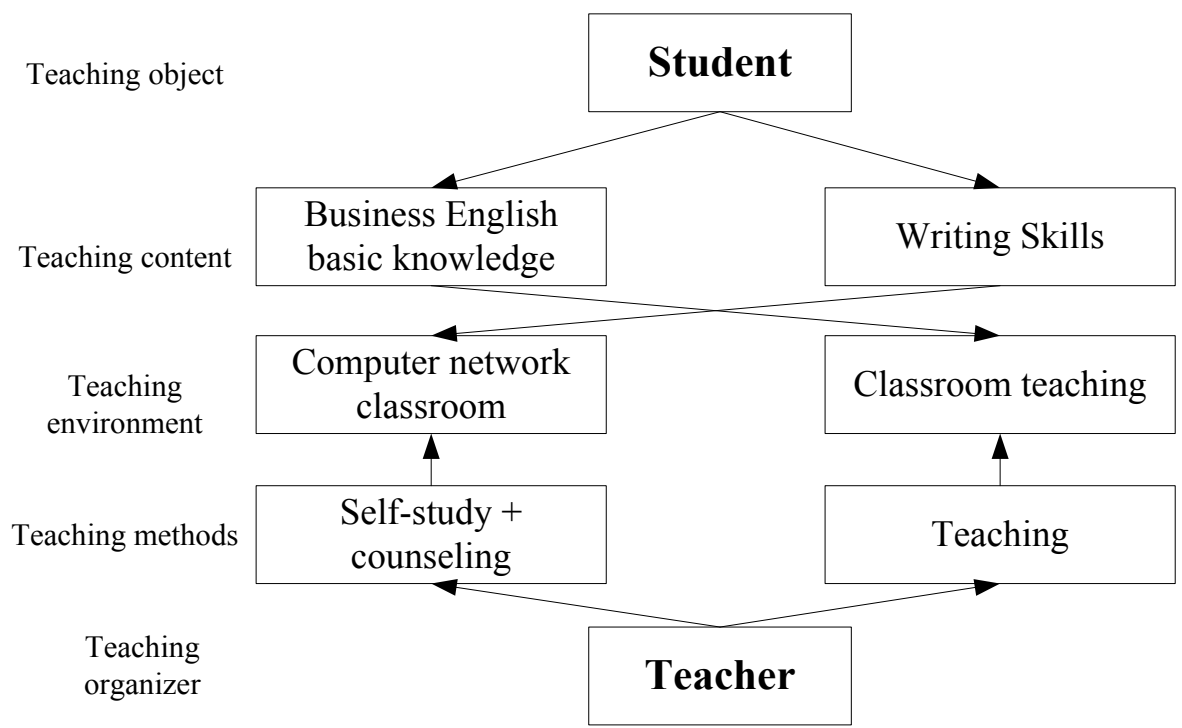

Fig. 2. The composition of interactive writing teaching model

The implementation principle of interactive teaching model in business application is to improve the students' writing level through practices of transcription and dictation. 


\subsection{Collaborative teaching model}

Collaborative teaching is taken on the web platforms; the students log on the web platform, for on-line communication, discussion with the peers, and joint-completion of writing learning tasks. In the network environments, the BE writing teaching model included teachers' learning instruction, instant discussion, document searching and collaborative learning [14]. Fig 3 lists every step of collaborative teaching model, starting with arranging homework and discussion questions, then making Q \& A between members of collaborative group and the teachers, and finally finishing the homework.

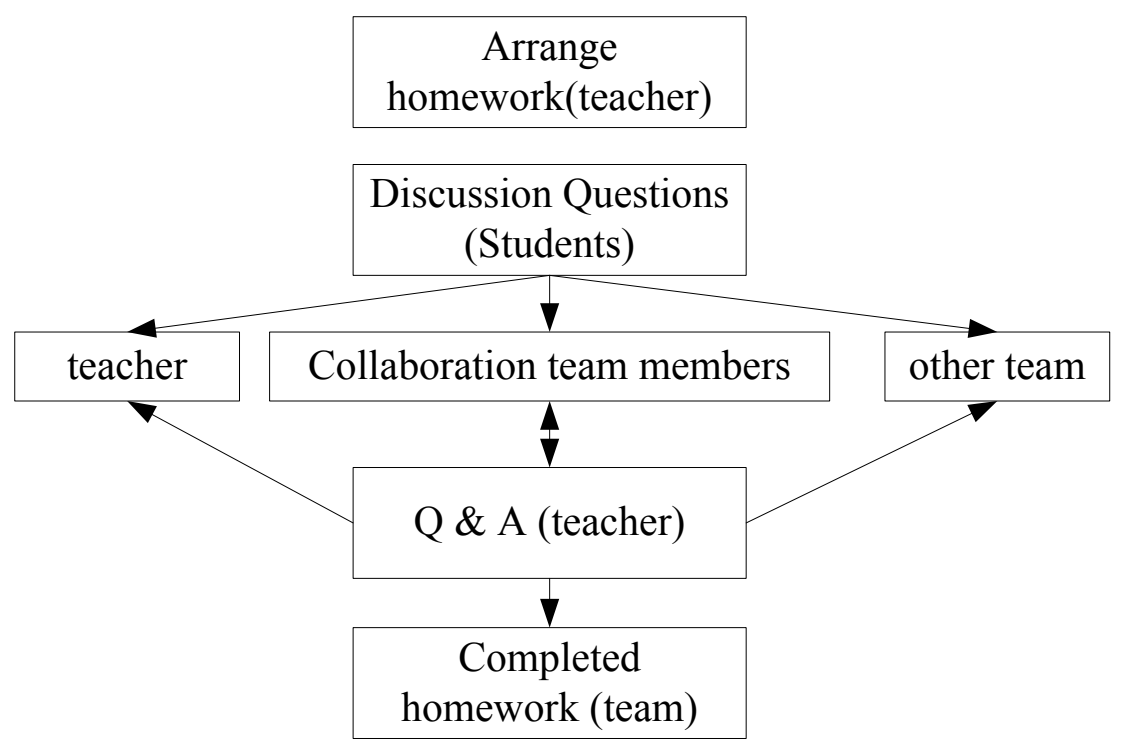

Fig. 3. Aspects of collaborative learning model

\subsection{Inquiry teaching model}

The inquiry teaching model is to utilize the web-based teaching platform, to design and develop on-line lessons, implement the on-line teaching, counsel the students and evaluate the web-education by inquiring. It is divided into two types: resource-based model and process-based model of inquiry teaching.

The resource-based inquiry model is one learning method, in which the students, on the basis of various resources, learn and grasp the science contents in groups by copying the process of scientific study, so as to experience, understand and apply the scientific research method at the same time, and to master the scientific research capacity and cooperation ability [15].

The process-based inquiry teaching model is for the teachers to utilize the eplatform to release teaching information and manage the teaching process. The released teaching information includes two major parts: teaching content and record 
content: the teaching content consists of multi-media materials, on-line courseware, on-line courses, also the teaching materials and the questions for student discussion; the record content means the arranged homework in the teaching process, and the records for class learning. In this model, the teachers can supervise the students in online courses, comment about their homework, and demonstrate the excellent writings of the students so as to improve their writing level by mutual learning.

\section{Computer-aided instruction (CAI)-based experimental design of BE writing}

To verify the application of CALL into BE writing, this paper selected the students of two parallel classes majored in Business English for one-semester teaching experimental study. The experiment was conducted in the forms of exam and questionnaire survey, by collecting the exam data and survey information of the contrast group and experimental group.

\subsection{Teaching experiment design}

\section{Experiment objective.}

1. Aim for the teaching model in which the students can better grasp the text features and pragmatic requirements of $\mathrm{BE}$;

2. Detect the experimental hypothesis, and verify whether the CALL model has positive effect on BE writing.

Experimental process. In the experiment, the contrast teaching was adopted for study. Select the students majored in Business English in one domestic foreign college as object of study, and then randomly choose two parallel classes: Class 1, the experimental class with 47 students; class 2 , the contrast class with 46 students. The experimental class applied the CAI model, and the contrast class the traditional English writing teaching. The experimental material was Basic Writing-Business English in Higher Education Press.

Pre-experimental exam. To determine the teaching method as the only variable in the experiment, the pre-experimental exam was taken to ensure the students' writing competence have no significant difference before the experiment.

Teaching content and teaching method. The students in experimental class, by teachers' guidance, started with learning about the writing characters of business English and understanding the related theories of humanism and constructivism etc. During the teaching of BE writing, PPT courseware had been prepared by the teacher, combined with the teaching material collected by the software such as Microsoft Student and Encyclopaedia Britannica etc. The course was taken in the simulated BE communication environment, by making full use of the computer multi-media and network technology, in order to cultivate the students' actual writing competence. Besides, in teaching process, the teachers can apply the collaborative teaching model 
by grouping the students, and also the interactive teaching model or inquiry teaching model can be adopted for BE writing.

In the contrast class, the traditional teaching method was applied. Firstly, the teachers taught some writing methods and techniques in class, interpreted the materials according to teaching textbook, then asked the students to practise writing by model-imitation, and finally checked/commented on their writings.

\subsection{Experiment results and analysis}

Questionnaire survey. The questionnaire included the following four topics and options:

(1) Which teaching model do you prefer?

A. Traditional teaching model

B. Computer-aided teaching model of business English writing

(2) For Computer-aided teaching model of business English writing, in what way is it helpful for you?

A. A large amount of corps for reading

B. Easy for modification

C. Timely evaluation for the homework

(3) In your opinion, whether can the Computer-aided teaching model of business English writing improve the teaching effect?

$\begin{array}{llll}\text { A. Yes } & \text { B. No C. No-obvious effec }\end{array}$

(4) In which teaching model do you have higher learning enthusiasm?

A. Traditional teaching model

B. Computer-aided teaching model

Issue the questionnaires to the 47 students in experimental class, and take back them. Refer to Table 3 for the collected statistics of questionnaire survey.

Table 1. Computer aided business English writing teaching questionnaire results statistics

\begin{tabular}{cccc}
\hline Code & Option A & Option B & Option C \\
\hline $\mathbf{1}$ & $9.2 \%$ & $90.8 \%$ & - \\
$\mathbf{2}$ & $18 \%$ & $71.3 \%$ & $9.7 \%$ \\
$\mathbf{3}$ & $89 \%$ & $1.5 \%$ & $9.5 \%$ \\
$\mathbf{4}$ & $8.9 \%$ & $91.1 \%$ & - \\
\hline
\end{tabular}

Table 1 shows that $90 \%$ students in experimental class prefer the computer-aided instruction (CAI) of English writing, but only 9.2\% prefer the traditional model. In the CAI model, one of its features "Easy for modification" was the most popular for the students in experimental class. $89 \%$ students agreed on the good teaching effect of the CAI model; $91 \%$ students thought that this model can further improve their learning initiatives.

Contrast of after-experiment scores. In order to better make quantitative analysis of BE writing competence between these two classes, the students in both classes were required to take the final exam at the end of one-semester teaching experiment. 
The exam adopted the uniform test paper, including English-Chinese translation of standard trade terms, error correction, cloze, dialogue completion and case writing. Refer to Table 2 for the exam scores:

Table 2. The average scores for each question type

\begin{tabular}{ccccccc}
\hline & $\begin{array}{c}\text { English-Chinese trade } \\
\text { terms mutual transla- } \\
\text { tion }\end{array}$ & $\begin{array}{c}\text { Error } \\
\text { correction }\end{array}$ & $\begin{array}{c}\text { Fill in } \\
\text { the } \\
\text { blank }\end{array}$ & $\begin{array}{c}\text { Complement the } \\
\text { conversation }\end{array}$ & $\begin{array}{c}\text { Case } \\
\text { writing }\end{array}$ & $\begin{array}{c}\text { Total } \\
\text { average } \\
\text { score }\end{array}$ \\
\hline $\begin{array}{c}\text { Control } \\
\text { group } \\
\text { Test }\end{array}$ & 13.2 & 7.6 & 8.2 & 13.2 & 38.9 & 80.9 \\
group & 13.6 & 7.9 & 9.4 & 13.3 & 44.7 & 88.8 \\
\hline
\end{tabular}

Table 2 shows that the average scores of every question type in CAI model are all higher than in traditional teaching model, esp., scoring 44.7 in the question type "case writing", about 6 points more than in contract class. And the total average score in experimental class was 7.9 points more than in contrast class, indicating the better results of CAI model.

Results analysis and expectation. By the teaching experiment, the subjective questionnaire survey and quantitative exams both have verified the better teaching effect for BE writing in the CAI model. It is seen that the CAI can provide more favourable writing environment for $\mathrm{BE}$ writing, improving the learning interest and efficiency on the basis of interactive, collaborative and inquiry teaching model between the students and teachers; CALL can help the students to understand the text features of BE writing, i.e. to be clear, concise, appropriate, courteous, considerate, specific, honest, individualized, complete and graceful; CAT better conforms to the pragmatic requirement of $\mathrm{BE}$ writing, making individualized expressions on the premise of maintaining the innate writing connotation.

\section{Conclusion}

This paper analyses the characters of $\mathrm{BE}$ writing and the present situation of $\mathrm{BE}$ writing teaching at home, and proposes the idea of teaching application of CALL into the BE writing. It starts with reviewing the related theoretical basis for the BE writing, then designs the interactive, collaborative and inquiry teaching models, and finally verifies the teaching effect of CAI model in the contrast experiment. The main conclusions are shown as follows:

The experimental class and contrast class were selected respectively for teaching experiment; with detailed design of teaching process, the quantitative and qualitative analysis was conducted for the teaching effect of CAI model by the means of questionnaire survey and exam.

The teaching experiment indicates that the CAI model is superior to the traditional model in terms of popularity and actual teaching effect.

To improve the $\mathrm{BE}$ writing competence, it is necessary to promote the CAI. 


\section{References}

[1] Wik, P., Hjalmarsson, A. (2009). Embodied conversational agents in computer assisted language learning. Speech Communication, 51(10), 1024-1037. https://doi.org/10.1016/ j.specom.2009.05.006

[2] Ohkawa, Y., Suzuki, M., Ogasawara, H., Ito, A., Makino, S. (2009). A speaker adaptation method for non-native speech using learners' native utterances for computer-assisted language learning systems. Speech Communication, 51(10), 875-882. https://doi.org/10.1016/j.specom.2009.05.005

[3] Zhu, J., Yang, B. (2011). On specialized english testing how to design a specialized english reading and writing test for business administration undergraduates. Energy Procedia, 13, 9826-9832.

[4] Zhang. (2014). Differences between chinese and western culture in business english teaching. International Journal of Technology Management, 91-93.

[5] Ma, Y. (2012). Studying the present situation of web-based english learning in business english schools. International Journal of Continuing Engineering Education and Life-Long Learning, 22(1/2), 24-35. https://doi.org/10.1504/IJCEELL.2012.047046

[6] Gasparetti, F., Micarelli, A., Sciarrone, F. (2009). A web-based training system for business letter writing. Knowledge-Based Systems, 22(4), 287-291. https://doi.org/10.1016/ j.knosys.2009.01.005

[7] Ip, N., Lee, J. (2015). Helping students find the 'write' way: an evaluation of a new english-in-the-discipline course in dissertation writing. Journal of Cardiovascular Electrophysiology, 14(4), 443-445.

[8] Apipongsathorn, R. (1986). Study of the relationship between a knowledge of english grammar and the ability to apply grammar to business writing with regard to the telephone organization of thailand's personnelrachakorn apipongsathorn. Neurobiology of Aging, 4(3), 169-170.

[9] Jones, L., Jones, L. (1996). New international business english. workbook. deutsche ausgabe. Biochemistry, 43(12), 3620-3627.

[10] Zirkin, Wayne S. (1968). Toward a theory of human development: the reconceptualization of a humanistic base for education. Journal of Pharmaceutical Sciences, 57(1), 164-7.

[11] Xianghong, Y. E. (2013). The ideological and political education guided by the constructivism learning theory. Journal of Central South University.

[12] Hamada, M. (2009). An integrated virtual environment for active and collaborative elearning in theory of computation. IEEE Transactions on Learning Technologies, 1(2), 117-130. https://doi.org/10.1109/TLT.2008.3

[13] Bzymek, Z. M., Vahidi, S., Spottiswoode, H. (2007). Solutions of the 21st centuryteaching computer-aided conceptual design. Computer-Aided Design and Applications, 4(1-4), 459-465. https://doi.org/10.1080/16864360.2007.10738565

[14] Jun, Su. (2013). Development status and countermeasures of the computer- aided english teaching. International Journal of Technology Management, 31-33.

[15] Last, R. W., King, P. K. (2010). The design and implementation of a computer assisted learning package for modern language teaching: a research progress report. British Journal of Educational Technology, 10(3), 194-197. https://doi.org/10.1111/j.1467-8535.19 79.tb00384.x 


\section{$7 \quad$ Author}

Xuefeng Li (1984), female, born in Harbin City, Heilongjiang Province, China. She is a lecturer with master degree at Xian Fanyi University, Xi'an 710105, China. Her research directions are Business English Teaching and Translation.

Article submitted 07 February 2018. Final acceptance 23 February 2018. Final version published as submitted by the author. 